\title{
Laser Velocimeter Measurements in the Stator of an Automotive Torque Converter
}

\author{
STEVEN B. AINLEY and RONALD D. FLACK* \\ Department of Mechanical, Aerospace, and Nuclear Engineering, University of Virginia, \\ Charlottesville, VA 22903-2442, USA
}

(Received 20 August 1998; In final form 20 May 1999)

\begin{abstract}
The flow field in the stator of a clear torque converter was studied using laser velocimetry. Five planes in the stator were studied at a speed ratio of 0.800 and three planes were studied at a speed ratio of 0.065 . Data complements previously available pump and turbine data. Flow in the stator inlet plane is highly non-uniform due to the complicated flow exiting the turbine. At the 0.800 speed ratio, separation regions are located in the $1 / 4$ and mid-planes in the corepressure corner region. In the 3/4 and exit planes, separation regions are located in the shellsuction corner. In the inlet plane a region of high velocities is located along the shell near the pressure side for a speed ratio of 0.800 . The high velocity region migrated to the shell-suction corner and suction side in the $1 / 4$ and mid-planes. The overall velocity field for the speed ratio of 0.065 changes significantly from the inlet plane to the mid-plane. The velocity magnitude generally decreases from the suction to the pressure side of the inlet plane and the general direction of the tangential velocity is from pressure-to-suction surface. At the speed ratio of 0.065 a strong secondary flow in the inlet from suction surface to pressure surface was seen. However, at the high speed ratio a moderate secondary flow in the inlet from pressure surface to suction surface was observed. Mass flow rates at the different planes are within the experimental uncertainty and also within the uncertainty of pump and turbine mass flow rates. The flow in the stator inlet plane are significantly influenced by the turbine relative blade position. The turbine influence on the mid-plane data is significantly less than on the inlet plane data. The influence of the pump blade position on the stator exit plane is small.
\end{abstract}

Keywords: Stators, Torque converters, Laser velocimetry

\section{INTRODUCTION}

Torque converters are commonly used in automobiles and other vehicles as a means of smooth torque transmission between the engine and the automatic transmission. The typical torque converter consists of a pump, a turbine, and a stator, and employs oil as the working fluid. Rotational energy from the engine is introduced into the fluid by the pump and extracted by the turbine. The

*Corresponding author. Tel.: (804)924-6213. Fax: (804)982-2037. E-mail: rdf@virginia.edu. 
non-rotating stator is placed between the turbine exit and pump inlet. Its function is to ideally create a zero pump inlet blade incidence angle at some design conditions.

The design of a torque converter is very complex due to a number of conditions. First, the turbomachine should operate efficiently at both on- and off-design conditions. However, the flow field changes drastically over the typical operating range; namely, incidence angles to all of the components change from large positive to large negative values over the operating range. Second, the flow is turned in the passages in two directions. As in any turbomachine, blade slip becomes a problem at offdesign conditions and the flow does not follow the blades. The problem is further complicated by the fact that the flow is also turned in the transverse direction in both the pump and turbine, usually in a short distance; namely, flow enters these components in the axial direction, rapidly is turned to the radial direction, and rapidly turned into the reverse axial direction. Thus, the torque converter stator is a complex axial flow device because the inlet and exit planes are directly after and before mixed-flow turbomachines and the boundary conditions are non-uniform.

\section{Previous Work}

A detailed review of ongoing torque converter work was recently published by Ainley et al. (1998) and other literature was reviewed by Gruver et al. (1996) and Brun and Flack (1997a). Thus, only some of the most recent publications on torque converters are reviewed herein for the sake of brevity.

Watanabe et al. (1997) recently used flow visualization and laser velocimetry to study the flow in stator passages for different thicknesses of vanes. They found that the thickness affected the flow fields and other parameters including the flow rate. They also found that the flow was non-uniform and separated regions were present regardless of the test conditions.

In 1988, General Motors Corporation, The University of Virginia, and Pennsylvania State
University, and in 1997 Michigan Technological University engaged in a large scale cooperative research project to systematically study the internal flow field of a series of automotive torque converters. The aim of this project was to develop both analytical as well as experimental tools to determine the flow field inside torque converters and its effect on the performance parameters. Simultaneously, at The University of Virginia internal flow velocities were measured, at the Pennsylvania State University pressures were measured, at Michigan Technological University cavitation was identified, and at General Motors a three-dimensional full NavierStokes flow solver code was developed to reproduce the experimental results. The same torque converter geometry and operating conditions were studied at all four research locations. Some results from this project have been published.

Marathe et al. (1996) and Marathe and Lakshminarayana (1995) used a five-hole probe to acquire pressure data at the turbine exit and stator exit of a torque converter. The flow fields were found to be highly three-dimensional and strong secondary flows were found. A separation region near the shell side of the stator passage was observed. The experimental data was in good agreement with the Navier-Stokes computational predictions at the stator exit for both "design" and "off-design" conditions. More recently, Dong et al. (1997) studied the unsteady flow fields at the turbine and pump exits of a larger diameter torque converter using the five-hole probe; they identified the jet, wake, and mixing regions. An overall review of the PSU efforts and an assessment of the results was conducted by von Backström and Lakshminarayana (1996).

Gruver et al. (1996) and Brun et al. (1996) used a facility to measure steady and unsteady velocities in the pump of the torque converter in threedimensions. Velocity fields were measured in the inlet, mid-, and exit planes of the pump at the speed ratios of 0.065 and 0.800 and pump rotational speed of 800 and $1100 \mathrm{rpm}$. The flow field in the pump inlet was found to be strongly dependent on the relative position between the pump and the stator. 
The pump exit velocity field was found to be influenced by the relative position between the pump and the turbine. Secondary flow was found in all three planes with the most significant occurring in the mid- and exit planes at the 0.800 speed ratio. Large separation regions were shown in the mid- and exit planes at the core and suction sides at both speed ratios. The pump inlet and exit flow field were seen to be highly unsteady.

Brun and Flack (1997a,b) used the same experimental facility to measure velocity fields in the turbine of the torque converter. The speed ratios of 0.065 and 0.800 were studied for the inlet, $1 / 4$, mid-, and exit planes of the turbine. Average flow velocity profiles were obtained for all the measurement planes and transient velocity fields were determined for all the planes except for the exit plane. The relative pump-turbine position exhibited a strong influence on the turbine inlet flow for both speed ratios. Significant separation regions were found in the $1 / 4$ and mid-planes at the 0.065 speed ratio.

More recently Ainley et al. (1998) and Flack et al. (1998) studied the flow field in the pump of the torque converter used by Gruver et al. (1996). They first examined in detail the effects of turbine/pump speed ratio and then considered the independent effects of rotational speed and oil viscosity. In general the flow in the pump exhibited the behaviors seen in conventional pumps. Some Reynolds number effects were seen.

\section{Motivations and Objectives}

Although torque converters receive widespread use and have received attention in the recent past, their internal flow characteristics remain misunderstood. Theoretical analysis of the torque converter has not developed to a level permitting design solely from computational results. Detailed velocity field experimental data, including velocity distribution, pressures, and turbulence intensities, are required for benchmarking and as boundary/initial conditions for computational flow solvers.

Three motivating factors drive the current research. First, the current design methods need to be improved in order to advance torque converter technology significantly; namely, velocity data is needed as a benchmark for verification of CFD methods. Second, since the torque converter operates very inefficiently at off-design conditions, optimization of the internal flow paths will yield an improved torque converter and better automobile fuel efficiency. A greater understanding of the fundamental flow behavior is required to design improved blade passages and shapes. Third, torque converter pumps and turbines have received more attention than stators. Yet the inlet and exit boundary conditions on the stator are complex due to the turbine and pump, which are mixed-flow turbomachines. The data presented herein complements the pump and turbine data currently available for the same torque converter.

A laser velocimeter was used in this study to nonintrusively measure velocity components in the stator of a Plexiglas model automotive torque converter. Velocities were measured in the inlet, quarter, mid-, $3 / 4$, and exit planes at two speed ratios. From the velocity data, flow non-uniformities and, in particular, separated regions were determined. Mass flow rates in each plane were calculated from the velocity data. Also, the influence of turbine and pump blade interactions were studied for the unsteady flow fields. The use of the obtained experimental results will lead to improved computational modeling of the flow field in the torque converter.

\section{EXPERIMENTAL FACILITY}

\section{Torque Converter Rig}

The entire experimental apparatus is shown schematically in Fig. 1. The torque converter pump was driven by a $18.6 \mathrm{~kW}$ motor and the rotational energy from the torque converter turbine was absorbed by a $130.5 \mathrm{~kW}$ eddy current dynamometer. A hydraulic system cooled, lubricated, and pressurized the torque converter rig. The pressures and temperatures throughout the test fixture and 


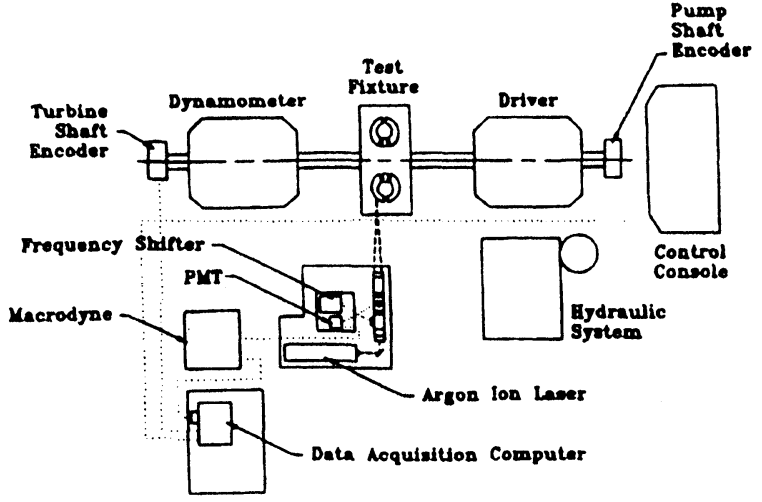

FIGURE 1 Experimental facility.

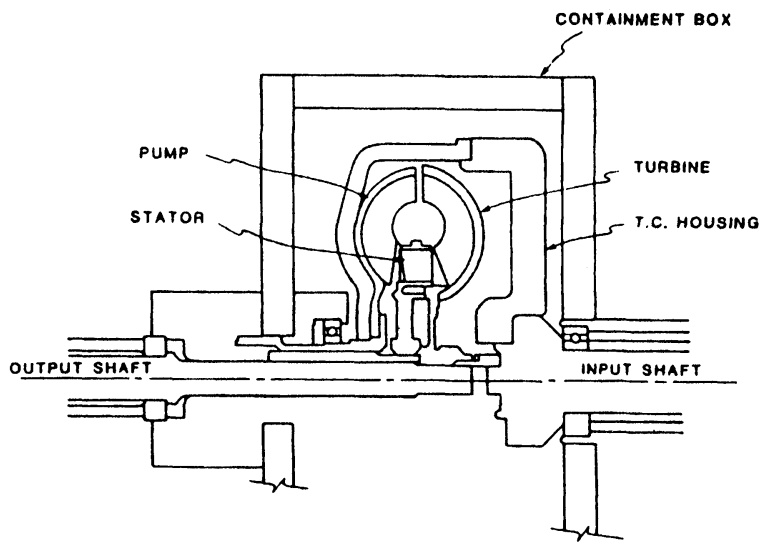

FIGURE 2 Plexiglas torque converter and containment box.

support system were monitored and controlled. The pump and turbine rotational speeds were controlled to within $1 \mathrm{rpm}$. The input and output torque were measured by load cells on the shafts.

The torque converter tested was a standard single stage automotive model with a diameter of $230 \mathrm{~mm}$ and was manufactured entirely of Plexiglas for optical accessibility. The torque converter was located in a rectangular containment box also made of Plexiglas as shown in Fig. 2. Both the torque converter and containment box were filled with Shellfiex 212 industrial oil, which has an index of refraction of 1.489 at $25^{\circ} \mathrm{C}$. This oil was chosen because it matched the index of refraction of the Plexiglas (nominally 1.490), which reduced

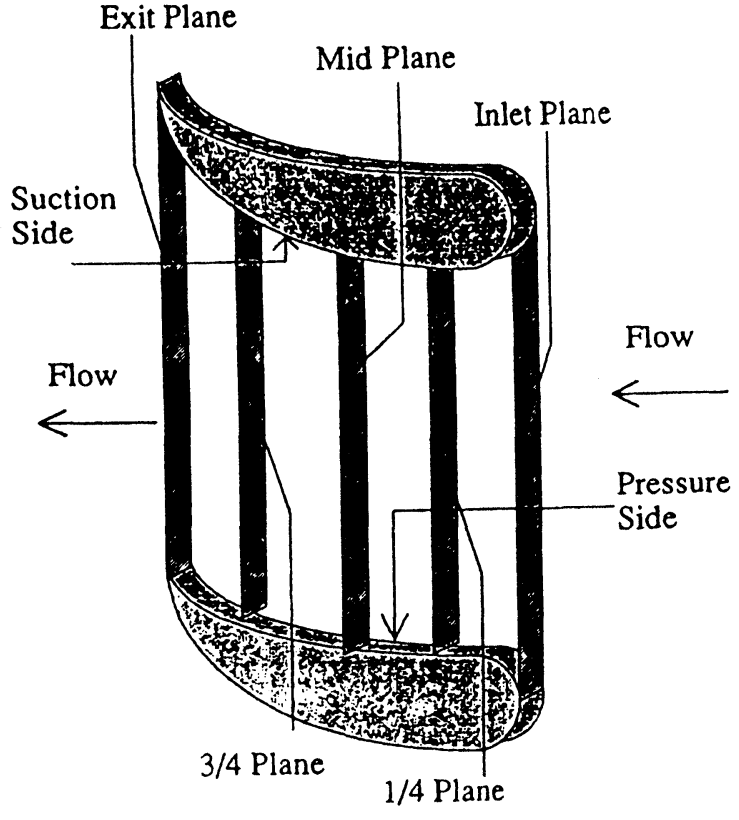

FIGURE 3 Stator passage geometry.

undesired laser beam refraction, reflection, and scattering. The density of the oil at $25^{\circ} \mathrm{C}$ is $899.1 \mathrm{~kg} / \mathrm{m}^{3}$ and the viscosity is $29 \mathrm{cSt}$ at $25^{\circ} \mathrm{C}$ and $19 \mathrm{cSt}$ at $40^{\circ} \mathrm{C}$.

The torque converter pump consisted of 27 identical blade passages, the turbine of 29 identical blade passages, and the stator of 19 passages. The pump and turbine blades were $1.1 \mathrm{~mm}$ thick and the shells were $2.67 \mathrm{~mm}$ thick. The stator blades and shell were milled from a single piece of Plexiglas and then glued to the core. In Fig. 3 the stator geometry and the five measurement planes are shown. The blade passage geometries and operating conditions were previously fully documented by By and Lakshminarayana (1995), Gruver et al. (1996) and By (1993). Also, the performance curves for the torque converter geometry were presented by Ainley et al. (1998).

\section{System}

A one-directional, frequency shifted, back scatter laser velocimeter system was used for this study. 


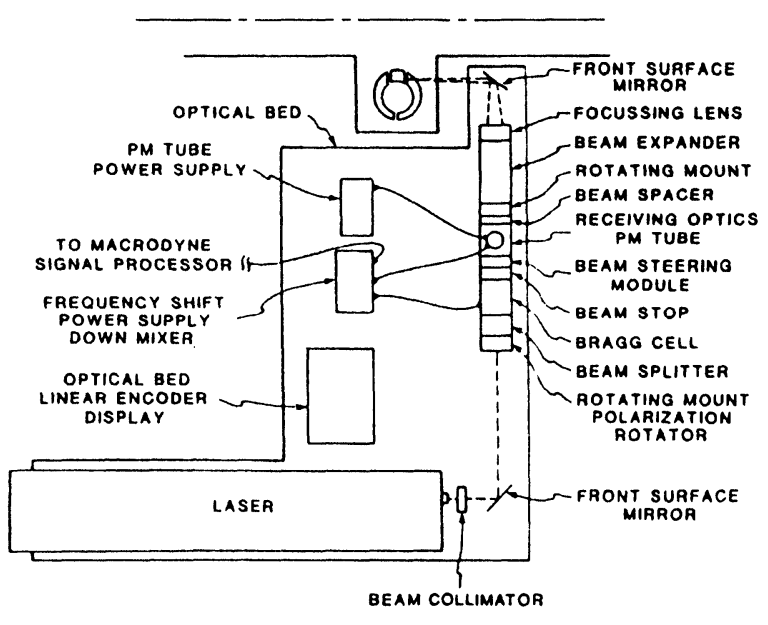

FIGURE 4 Laser velocimeter and optics.

A 2-watt argon-ion laser, operated at $50 \mathrm{~mW}$ and at a wavelength of $514.5 \mathrm{~nm}$, was employed. The laser and the accompanying laser velocimeter optics were mounted on a mill table as shown in Fig. 4 to provide a stable vibration free base. The position of the table and, thus, the measurement location (probe volume) was computer controlled by 3 -axis stepper motors, linear encoders, and a digital read-out.

The single laser beam was split into two equal intensity beams by a beam splitter module. One beam was frequency upshifted using a Bragg cell in order to eliminate velocity directional ambiguity. Beam spacers, expanders, and a focusing lens (focal length of $250 \mathrm{~mm}$ or $350 \mathrm{~mm}$, depending on the measurement requirements) were employed to first reduce the probe volume size and then focus the laser beams to cross in the test section. To provide for light scattering, the oil was seeded with metallic coated glass particles which have an average diameter of $12 \mu \mathrm{m}$ and have a density approximately that of the oil. The scattered light from the particles was focused into a $0.02 \mathrm{~mm}$ diameter pin-hole and then converted to a voltage signal by a photomultiplier tube (PMT). The PMT output signal (Doppler signal) was amplified, sent to a burst counter processor, and converted to digital velocity output. The burst counter processor employed band-pass filtering, an adjustable minimum threshold, and a $5 / 8$ peak counter comparator to validate burst signals. The digital velocity information was read into a data acquisition computer via a high speed digital I/O card. Simultaneously with each velocity signal, the instantaneous angular positions of the pump and turbine were read in using two 10-bit shaft encoders (1024 circumferential positions) attached to the pump and turbine shafts.

The measurement uncertainty of the velocity was due to the uncertainty of the clock counter in the digital processor, uncertainty in the beam crossing angle, and the uncertainty of using a finite number of samples to approximate a true distribution; this uncertainty was typically $\pm 0.05 \mathrm{~m} / \mathrm{s}$ with $95 \%$ confidence. Due to the small difference of index of refraction of the oil and plastic, a translational uncertainty of the probe volume position was also present and was approximately $0.05 \mathrm{~mm}$. This probe volume position uncertainty was statistically added with the uncertainty in the angular position, which resulted in a typical uncertainty in the velocity of $0.07 \mathrm{~m} / \mathrm{s}$, when velocity gradients were present. As a result, the total uncertainty in velocity was $0.11 \mathrm{~m} / \mathrm{s}$.

\section{Procedure}

Although the LV system was one-directional, different velocity components were measured by rotating the beam splitter and realigning the optics for each component. The axial and tangential velocity components were measured by aligning the laser velocimeter beams perpendicular to the torque converter shaft, while for the radial component the beams were aligned parallel to the shaft (Fig. 1 shows the arrangement to measure the axial component and Fig. 4 shows the arrangement to measure the radial component). All three components of velocities were obtained at all measurement locations.

Measurement plane locations were determined by first using reference points in the stator and the known stator dimensions. The measurement locations were determined by finding the coordinates of the four corners of the stator blade passage relative 
to the chosen reference point and interpolating a 7 point by 9 point measurement plane grid. This was done separately for each of the five measurement planes and this procedure was repeated for the measurement of each velocity direction. The probe volume was placed for the desired measurement locations in the stator with a total accuracy of the absolute position of $0.05 \mathrm{~mm}$ in any direction.

Five measurement planes were studied in the stator: each stator measurement plane consisted of 7 evenly spaced locations in the pressure-to-suction direction and 9 evenly spaced locations coreto-shell positions for a total of 63 positions. Figure 3 shows the stator measurement planes and defines the pressure and suction sides of the passage.

The torque converter was run at two different test conditions. The test conditions for the stator are shown in Table I. In all cases the stator was stationary and the pressure was $2.1 \mathrm{~atm}$. Oil temperatures are given in Table I. The torque converter was run for approximately one hour before any data was taken so that the pressures and temperatures of the system could reach steady state.

\section{Reynolds Numbers}

The Reynolds numbers were calculated for the operating conditions for the mid-plane and listed in Table II. The Reynolds number $\left(\operatorname{Re}=V \cdot D_{\mathrm{h}} / \nu\right)$ was calculated based on the average through-flow

TABLE I Test conditions

\begin{tabular}{lcc}
\hline & Condition 1 & Condition 2 \\
\hline Speed ratio & 0.065 & 0.800 \\
Pump speed & $800 \mathrm{rpm}$ & $1100 \mathrm{rpm}$ \\
Turbine speed & $52 \mathrm{rpm}$ & $880 \mathrm{rpm}$ \\
Temperature & $37^{\circ} \mathrm{C}$ & $30^{\circ} \mathrm{C}$ \\
\hline
\end{tabular}

TABLE II Reynolds numbers (mid-plane)

\begin{tabular}{lc}
\hline SR & Reynolds number \\
\hline 0.065 & 2581 \\
0.800 & 1474 \\
\hline
\end{tabular}

velocity, $V$, and the hydraulic diameter at the midplane, $D_{\mathrm{h}}(0.0148 \mathrm{~m})$.

\section{Data Reduction}

The average velocities and periodic transient velocities were studied herein. The first method of data evaluation was used to find the overall average velocity field for a particular measurement plane without respect to the position of either of the other two rotating components. The second method was used to determine the velocity field for a particular plane in the stator based upon either the pump or turbine instantaneous angular position.

The collection of data for the average velocity measurements required only enough samples to obtain a good statistical representation of the actual velocity. The instantaneous angular positions of the turbine and the pump were not required for the average velocity studies. Four hundred measurements were taken for each stator measurement location.

Second, the method used to examine the unsteady velocities was based upon that of Brun and Flack (1994), who demonstrated the ability of laser velocimetry to be used to measure time-dependent, unsteady but periodic flow fields in turbomachines. The transient velocities were studied in only selected planes herein. The resolution of each of the shaft encoders was 1024 angular positions. Since 29 identical turbine blade passages exist, 35 different angular turbine positions exist for the passing of each blade passage. The pump had 27 identical blade passages and 37 unique angular positions existed. These instantaneous angular positions of the rotating components were recorded at the time each velocity measurement was taken. With this information the data for each plane was organized into 35 or 37 unique groups. Each of these groups represented an independent instantaneous flow field. For each measurement position enough samples were taken so that a statistically sufficient number of samples was recorded for each turbine or pump position. A population is sufficient for calculation of an average if the number of samples 
exceeds 30. For example, with 35 possible turbine positions and 30 samples desired per position, more than 1110 velocity readings are needed for each location. However, due to unequal population sizes, 5000 samples were needed for each measurement position.

\section{RESULTS}

Three-dimensional and two-dimensional vector plots and through-flow contour plots were studied for three planes at the 0.065 speed ratio and for five planes at the 0.800 speed ratio. The measurement planes for the 0.065 speed ratio include the inlet, mid-, and exit planes. The inlet, $1 / 4$, mid-, $3 / 4$, and exit planes were studied for the 0.800 speed ratio. Unsteady velocity fields are shown for the 0.800 speed ratio to show the effect of the turbine and the pump on the stator flow field. Transient throughflow velocities due to turbine influence are presented for the inlet and the mid-plane and similar data due to pump influence are shown for the exit plane. Further details can be found in Ainley (1994).

\section{Average Velocities}

\section{Speed Ratio of 0.065}

The average velocity field of the stator inlet for the speed ratio of 0.065 is presented in Figs. 5-7. Figure 5 represents the three-dimensional velocity vector field. The highest velocities are located at the shell-suction corner and the lowest velocities are at the core-pressure corner. Overall velocities steadily

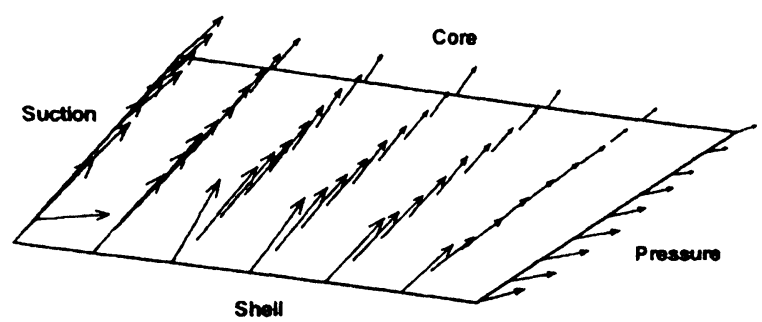

FIGURE 5 Average total velocity vectors at the inlet plane for $\mathrm{SR}=0.065$ decrease from the shell-suction corner to the core-pressure corner. Figure 6 shows the average through-flow velocities in the inlet plane to be highest near the shell-suction corner with peak velocities of about $5.8 \mathrm{~m} / \mathrm{s}$. The region of low through-flow velocities is located along the pressure side of the plane with the lowest velocities about $0.7 \mathrm{~m} / \mathrm{s}$. The velocities near the center of the plane are about $3.9 \mathrm{~m} / \mathrm{s}$. Although a moderate gradient of the through-flow velocity is noted in the pressure surface to suction surface direction, minimal gradient is noted in the core-to-shell direction.

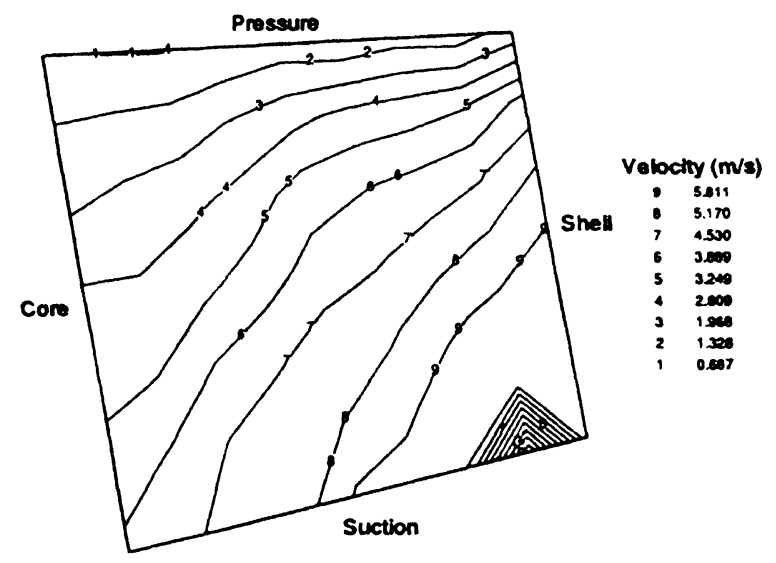

FIGURE 6 Average through-flow velocity contours at the inlet plane for $\mathrm{SR}=0.065$

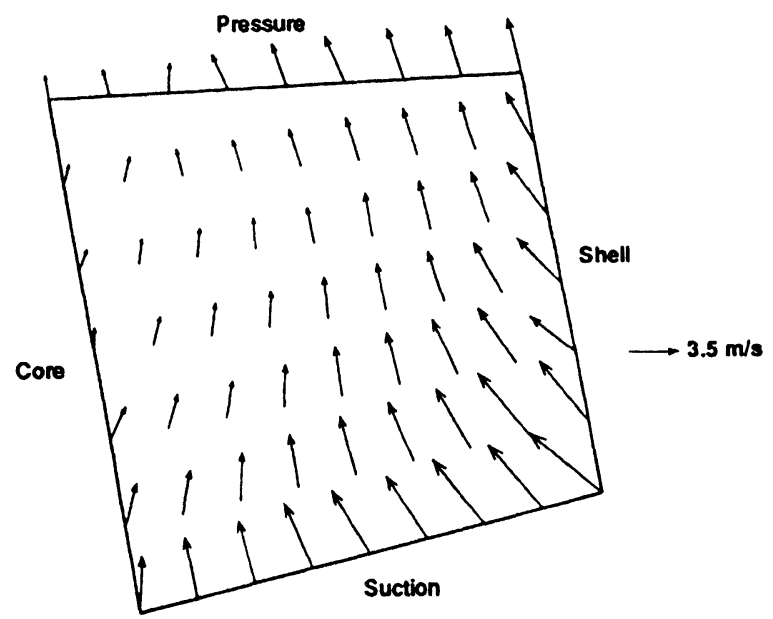

FIGURE 7 Average secondary velocities in the inlet plane for $S R=0.065$. 
Brun and Flack (1997a) also did not report a strong core to shell gradient for the turbine exit for this condition. The average radial and tangential flow is shown by a two-dimensional vector plot (Fig. 7). Again, the highest velocities are located at the shell-suction corner with the highest velocities (radial and tangential combined) close to $6.4 \mathrm{~m} / \mathrm{s}$. The velocities in the center of the plane are about $3.5 \mathrm{~m} / \mathrm{s}$. The general direction of the tangential flow is suction to pressure. The radial flow varies from shell-to-core near the shell side to core-to-shell near the core side of the inlet plane.

In the mid-plane the highest three-dimensional velocities are located in center of the passage. The velocities are significantly lower along the suction side especially at the $50 \%$ core-to-shell position. Also, the velocities along the shell side of the plane are lower than the center velocities. The throughflow velocities (Fig. 8) are highest slightly to the shell and suction sides of the plane center. The peak velocities in this region are $8.7 \mathrm{~m} / \mathrm{s}$. The velocities steadily decrease towards the core-pressure corner to about $2.7 \mathrm{~m} / \mathrm{s}$. At about $40 \%$ shell to core along the suction side the velocities are $0.7 \mathrm{~m} / \mathrm{s}$ or lower. The secondary velocities are about $1.7 \mathrm{~m} / \mathrm{s}$ in the center of the plane and increase to about $5.5 \mathrm{~m} / \mathrm{s}$ at the core-suction corner. The general direction of the tangential flow is pressure-to-suction surface. The radial velocities reverse from shell-to-core in direction near the pressure side to core-to-shell along the suction side of the plane.

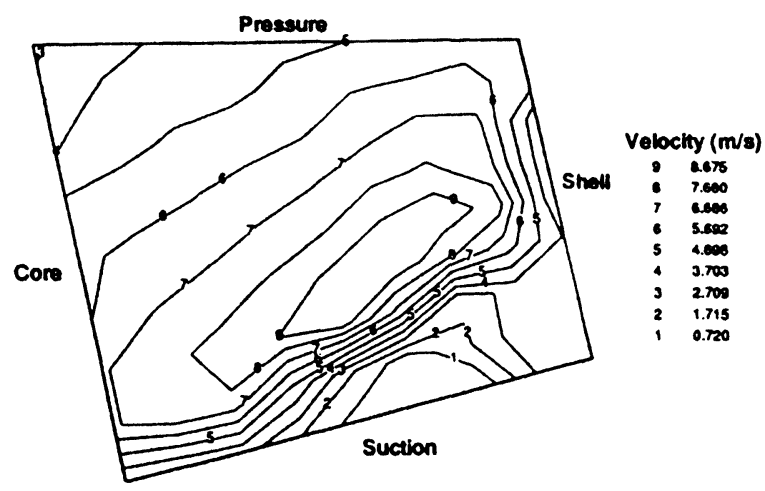

FIGURE 8 Average through-flow velocity contours at the mid-plane for $\mathrm{SR}=0.065$.
For the exit plane a three-dimensional low velocity region is located midway from core-to-shell near the suction side. The velocity field is fairly uniform in the $10-50 \%$ pressure-to-suction region. The through-flow velocities (Fig. 9) are greatest in the aforementioned region with peak velocities of about $5.4 \mathrm{~m} / \mathrm{s}$. The velocities in the center of the plane range from about 2.5 to $4.0 \mathrm{~m} / \mathrm{s}$ and are fairly consistent from core-to-shell. The lowest velocities are located in the core-suction corner and are about $0.5 \mathrm{~m} / \mathrm{s}$. The secondary velocities are fairly consistent at about $8.5 \mathrm{~m} / \mathrm{s}$ throughout the plane except near the suction side where the velocities are as low as $1.7 \mathrm{~m} / \mathrm{s}$. The general direction of the tangential flow is from pressure-to-suction and is significantly greater than the radial velocity. The direction of the radial velocity is shell-to-core near the pressure side and is close to zero near the suction side of the exit plane.

In summary, the overall velocity field for the speed ratio of 0.065 changes significantly from the inlet plane to the mid-plane. There is a general decrease in velocity magnitude from the suction to the pressure side of the inlet plane and the general direction of the tangential velocity is from pressureto-suction. In the mid-plane the highest velocities are located in the center of the plane and a region of

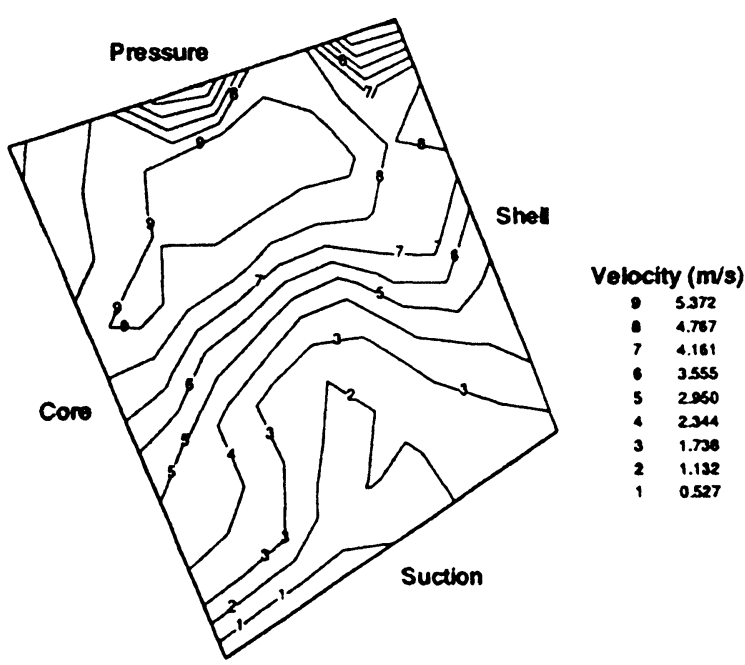

FIGURE 9 Average through-flow velocity contours at the exit plane for $\mathrm{SR}=0.065$. 
low velocity is located along the suction side of the plane. A strong secondary flow in the inlet from suction surface to pressure surface was seen. In the mid- and exit planes the tangential velocities are oriented in the pressure-to-suction direction (opposite from the inlet plane). The exit plane velocity field is similar to the mid-plane velocity field except there is a greater tangential velocity component and a lesser through component.

\section{Speed Ratio of 0.800}

The three-dimensional velocity field (Fig. 10) for the inlet plane is non-uniform. A band of low velocities in the pressure-to-suction direction is noted close to the shell at the pressure side and midway from core-to-shell at the suction side. Figure 11 represents the through-flow velocities. Peak velocities of about $3.0 \mathrm{~m} / \mathrm{s}$ are located near

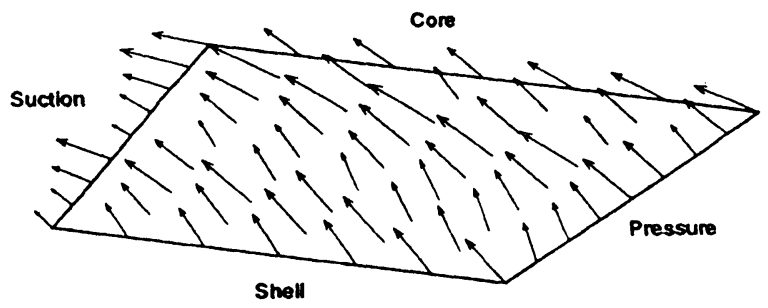

FIGURE 10 Average total velocity vectors at the inlet plane for $\mathrm{SR}=0.800$

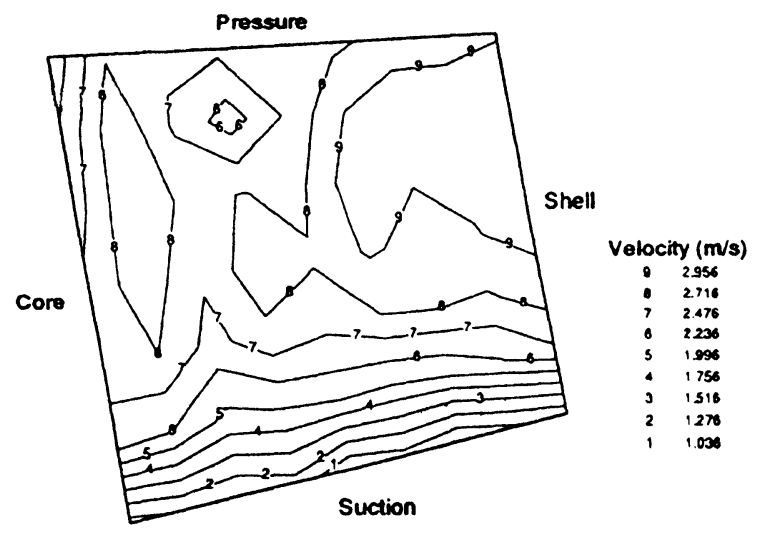

FIGURE 11 Average through-flow velocity contours at the inlet plane for $S R=0.800$. the shell-pressure corner. Velocities in the center of the plane are $2.7 \mathrm{~m} / \mathrm{s}$. Along the suction side the velocities are as low as $1.0 \mathrm{~m} / \mathrm{s}$ and these velocities are consistent from core-to-shell. As for $\mathrm{SR}=0.065$, a moderate gradient of the through-fow velocity is noted in the pressure surface to suction surface direction but minimal gradient is noted in the coreto-shell direction. Again, Brun and Flack (1997a) did not report a strong core to shell gradient for the turbine exit for speed ratio. Figure 12 shows the radial and tangential velocity field for the inlet plane. The highest velocities are about $7.6 \mathrm{~m} / \mathrm{s}$ and are located in a region stretching from the coresuction corner to the pressure side midway from core-to-shell. Lower velocities of about $1.7 \mathrm{~m} / \mathrm{s}$ are located just to the shell side of the aforementioned region. The direction of the radial velocities is again small except near the core side of the plane where the direction is core-to-shell. The tangential velocities are pressure-to-suction in direction.

The three-dimensional velocity field for the $1 / 4$ plane of the stator is relatively uniform throughout the plane except near the pressure side. A small separation region is present in the core-pressure corner of the plane. The velocities remain low along the pressure side towards the shell-pressure corner. Peak through-flow velocities of about $4.2 \mathrm{~m} / \mathrm{s}$ are located in the shell-suction corner. Throughout

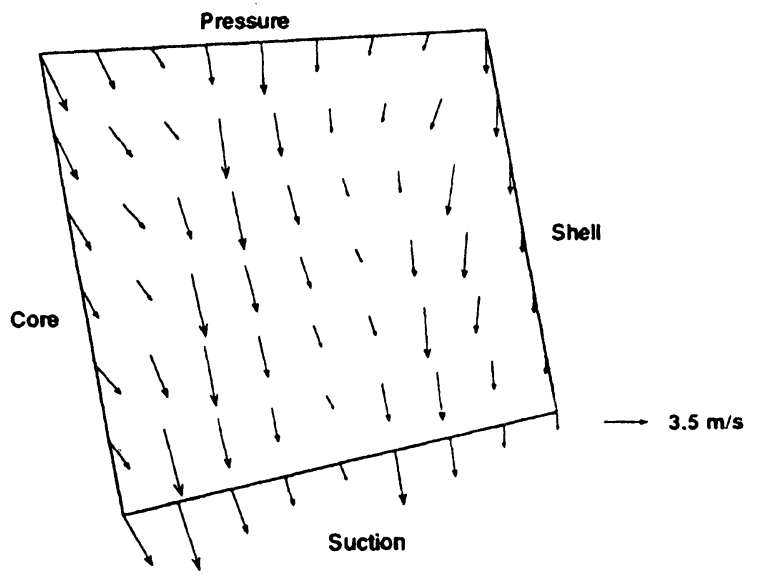

FIGURE 12 Average secondary velocities in the inlet plane for $\mathrm{SR}=0.800$. 
most of the plane the velocities are in the range of $3.6-4.2 \mathrm{~m} / \mathrm{s}$. A small region of negative flow is located in the core-pressure corner and the velocities are close to $0.0 \mathrm{~m} / \mathrm{s}$ along the entire pressure side of the $1 / 4$ plane. The secondary velocities range from about $0.9 \mathrm{~m} / \mathrm{s}$ in the shell-suction corner to about $4.7 \mathrm{~m} / \mathrm{s}$ along the core side midway from pressure-to-suction. The separation in the corepressure corner is again evident. The direction of the tangential flow is from pressure-to-suction. The direction of the radial flow varies from shell-to-core in the shell-pressure corner to approximately zero near the core side to core-to-shell in the shellsuction corner.

A larger separation region is present in the midplane than in the $1 / 4$ plane and is again located in the core-pressure corner. The three-dimensional velocity field is uniform in direction away from the separation region. The highest velocities are located toward the suction side and especially nearer the core side than the shell side. The peak through-flow velocities (Fig. 13) are about $5.4 \mathrm{~m} / \mathrm{s}$ and located along the suction side of the plane near the core. The velocities range from about $4.0-4.7 \mathrm{~m} / \mathrm{s}$ in the center of the plane. Along the pressure side the velocities are close to $0.0 \mathrm{~m} / \mathrm{s}$ and are negative in direction in the core-pressure corner. Peak secondary velocities of about $3.8 \mathrm{~m} / \mathrm{s}$ are located near the core-suction region. Velocities in the

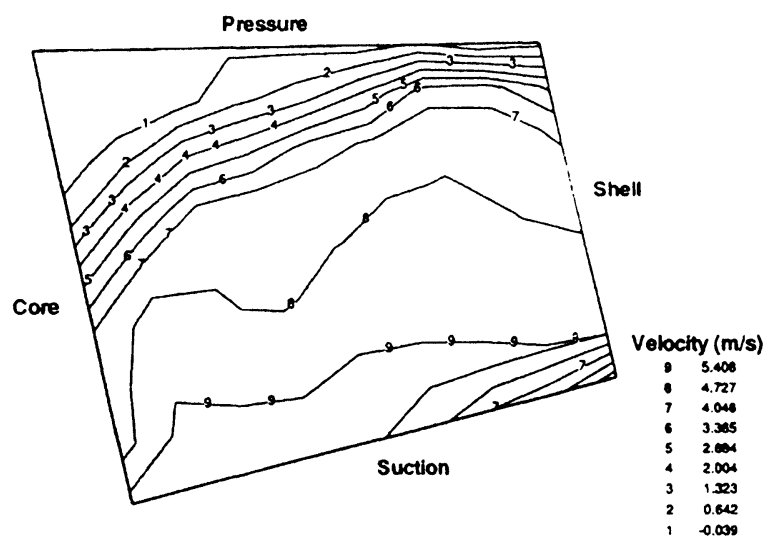

FIGURE 13 Average through-flow velocity contours at the mid-plane for $\mathrm{SR}=0.800$. center of the plane are about $3.5 \mathrm{~m} / \mathrm{s}$ and decrease towards the shell side to about $1.7 \mathrm{~m} / \mathrm{s}$. The tangential velocities are pressure-to-suction in direction except for the separation region. The radial velocities are close to zero near the core and suction sides and shell-to-core in direction near the shellpressure area.

A large separation region is located in the shellsuction corner of the plane of the $3 / 4$ plane. A small separation region is present in the core-pressure corner at the same location of the separation region in the mid-plane. The velocities in the center of the plane are fairly uniform. The highest through-flow velocities are located midway from pressure-tosuction along the shell side of the plane. The peak velocities in this region are about $4.6 \mathrm{~m} / \mathrm{s}$. The velocities rapidly decrease toward the suction side where the lowest velocities are about $0.0 \mathrm{~m} / \mathrm{s}$. A region of low velocities is also located along the pressure side especially near either the core side or shell side. Velocities in these regions are also close to zero. The radial and tangential velocity field is relatively constant in non-separated region. Typical velocities in the center of the plane are about $4.4 \mathrm{~m} / \mathrm{s}$. The tangential flow direction is pressureto-suction and the radial flow is approximately zero or slightly in the shell-to-core direction except in the two separation regions in which case the velocities are non-uniform.

A separation region remains evident in the shellsuction corner of the exit plane. A small separation region is located in the shell-pressure corner. Velocities are highest midway from pressure-tosuction and decrease towards the suction side of the exit plane. The highest through-flow velocities (Fig. 14) are located along the shell closer to the pressure side than the suction side. Peak velocities in this region are about $4.1 \mathrm{~m} / \mathrm{s}$. Velocities in the separation region in the shell-suction corner are about $0.0 \mathrm{~m} / \mathrm{s}$. In the center of the plane the velocities are about $3.6 \mathrm{~m} / \mathrm{s}$. Radial and tangential combined velocities range from about $3.5-4.4 \mathrm{~m} / \mathrm{s}$ throughout much of the plane with the peak velocities located near the core-suction area. Radial velocities are slightly in the shell-to-core direction 

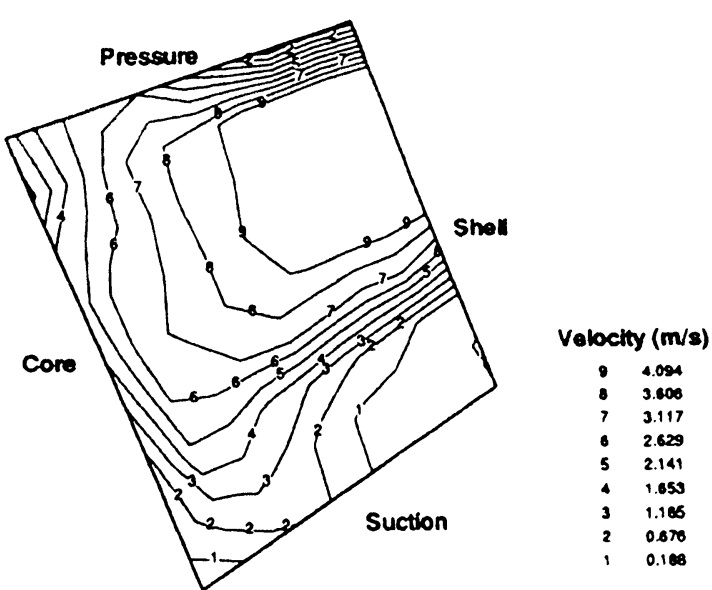

FIGURE 14 Average through-flow velocity contours at the exit plane for $\mathrm{SR}=0.800$.

except along the suction side of the plane. Again, the tangential velocities are in the pressure-tosuction direction.

In summary, in the inlet plane a region of high velocities is located along the shell near the pressure side. The high velocity region migrated to the shellsuction corner and suction side in the $1 / 4$ and midplanes. Also, a separation region develops in the $1 / 4$ plane and mid-plane in the core-pressure corner. The separation region is located in the same region in the $3 / 4$ plane but is smaller than in the mid-plane. In the $3 / 4$ and exit planes, large separation regions are located in the shell-suction corner. In all planes the general direction of the tangential velocity is from pressure-to-suction surface and the radial velocity component in most cases is small.

\section{One-Dimensional Averages}

The average velocity vector for each plane and operating condition in the stator was calculated. These calculated velocity vectors provide a useful summary of the stator flow field. This information may be used for torque converter performance prediction and design using a one-dimensional analysis. The velocity vector is defined by the magnitude and two angles. The magnitude and angles were weighted (multiplied by the local area and
TABLE III Average velocity summary

\begin{tabular}{lccc}
\hline $\begin{array}{l}\text { Measurement } \\
\text { plane }\end{array}$ & Magnitude $(\mathrm{m} / \mathrm{s})$ & $\theta$ (degrees) & $\phi$ (degrees) \\
\hline SR $=0.065$ & & & \\
$\quad$ Inlet & 3.93 & 12.3 & -41.2 \\
Mid & 5.65 & -6.3 & 24.0 \\
$\quad$ Exit & 5.95 & -19.7 & 56.8 \\
SR $=0.800$ & & & \\
$\quad$ Inlet & 3.41 & -13.7 & 48.0 \\
1/4 & 3.90 & -4.3 & 29.3 \\
Mid & 4.07 & -2.8 & 30.4 \\
3/4 & 3.66 & -10.3 & 42.0 \\
Exit & 3.86 & -29.8 & 53.3 \\
\hline
\end{tabular}

divided by the average area of the plane) by the area which each velocity vector represents.

The two angles which make up the velocity vector are defined as follows: $\theta$ is the angle the resultant velocity vector makes with the through-flow velocity vector if projected onto the radial-axial coordinate plane and, $\phi$ is the angle the resultant velocity vector makes with the through-flow velocity vector if projected onto the tangential-axial coordinate plane. The positive angle $\theta$ exists in the axial-radial coordinate plane, originates at the through-flow velocity vector and increases in the direction of the torque converter core. The positive angle $\phi$ exists in the axial-tangential coordinate plane, originates at the through-flow velocity vector and increases in the direction of the pump rotation. A velocity vector with no radial or tangential components has an angle $\theta$ of $0^{\circ}$ and an angle $\phi$ of $0^{\circ}$. Table III shows the velocity summary for the stator.

\section{Periodic Transient Velocities}

The velocity flow field in the stator is unsteady but periodic. The turbine has 35 possible angular positions relative to the stator. Thirty-five independent velocity fields were calculated for the stator planes at the speed ratio of 0.800 . When all the independent velocity fields are placed together in sequence, the transient effects of the turbine on the stator can be seen. A turbine position of 1 or 36 means that the center of the turbine blade is in-line 
with the center of the stator blade on the pressure side of the stator blade passage.

Figures 15 and 16 show some typical results: the through-flow velocity field for the stator inlet plane at the speed ratio of 0.800 . Figure 15 shows the through-flow velocity field in the stator upstream plane for a turbine position of 1 . There is one region of high velocity near the shell and another region of high velocity near the core side of the plane. By examining the series of through flow plots for the 35 different turbine positions the movement of the two regions across the stator upstream plane in the

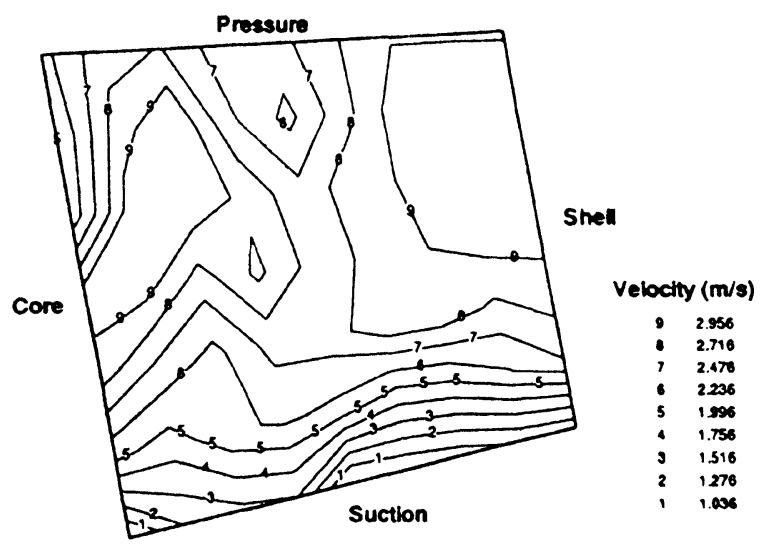

FIGURE 15 Instantaneous through-flow velocity contours at the inlet plane for $\mathrm{SR}=0.800$ and turbine position 1 .

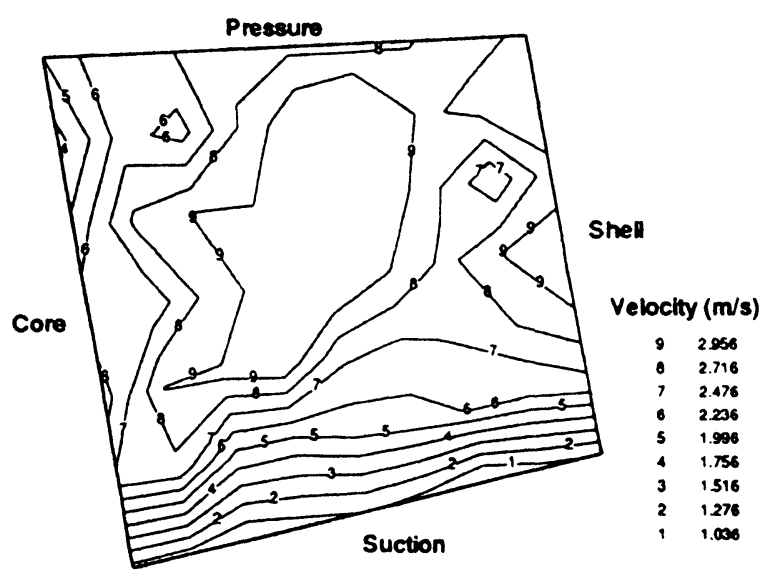

FIGURE 16 Instantaneous through-flow velocity contours at the inlet plane for $\mathrm{SR}=0.800$ and turbine position 15 . core-to-shell direction can be seen. Figure 16 shows a single region of high velocity in the center of the plane (turbine position is 15). Two regions of high velocities can again be seen. The velocities along the pressure and the along the suction sides of the plane remain relatively constant for each turbine position.

Much smaller velocity fluctuations are present in the mid-plane compared to the inlet plane. There is still a migration of a high velocity region across the plane from the core side to the shell side, but the magnitude of the fluctuations is smaller than in the upstream plane. No periodic fluctuations correlated with the turbine were noted in the exit plane and minimal were seen in the $3 / 4$ plane.

To summarize typical fluctuations Fig. 17 is presented. In this figure the velocities in the center of the inlet and mid-planes are shown for the 35 different turbine positions. Position 36 is the same as position 1 due to the periodicity. As can be seen, in the inlet plane the velocity varies from 2.4 to $3.2 \mathrm{~m} / \mathrm{s}$. In the mid-plane the velocity varies from 4.4 to $4.8 \mathrm{~m} / \mathrm{s}$.

The stator flow field is affected through the midplane by the relative position of the turbine blades

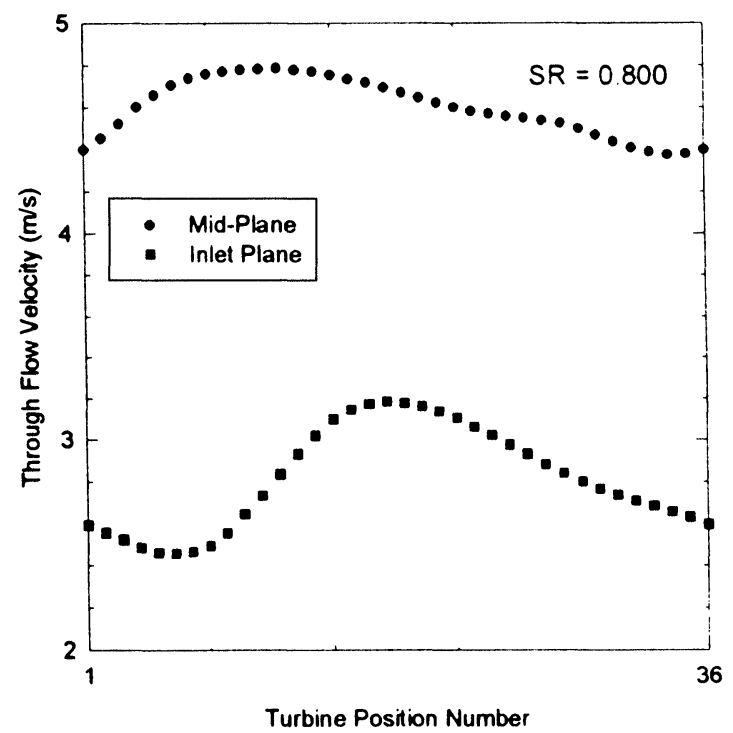

FIGURE 17 Transient through-flow velocity at the passage center as a function of turbine position. 
with respect to the stator. Two regions of high velocity are present in the inlet plane for most relative turbine positions. This is due to the greater number of turbine blades than stator blades (29 turbine blades and 19 stator blades). In many cases the effects of two separate turbine blade passages (and thus two jets) are affecting the stator flow field at the same point in time. The high velocity regions were seen to move across the stator upstream plane in the core-to-shell direction and not in the pressure-to-suction direction. The turbine blades are not directly in-line with the stator blades but rather cross the stator blade passage at an angle. Therefore, when the turbine blade passage passes the stator passage the high velocity regions move from the core to the shell.

Figures 18 and 19 show some typical results for the effects of the pump on the stator flow field: the through-flow velocity field for the stator exit plane at the speed ratio of 0.800 . Figure 18 shows the through-flow velocity field in the exit plane for a pump position of 1 . There is one region of high velocity near the shell and a low velocity region near the shell/suction quadrant. Figure 19 shows a very similar flow field (pump position is 17), and is also similar to the time averaged plot (Fig. 14).

To summarize typical fluctuations Fig. 20 is presented. In this figure the velocities in the center of the exit plane are shown for the 37 different pump positions. Position 38 is the same as position 1 due to the periodicity. As can be seen, in the velocity varies from 3.7 to $3.9 \mathrm{~m} / \mathrm{s}$. All of the transient flow field plots based on pump position show that the effect on the flow in the exit plane is small.

\section{Mass Flow Rates}

The mass flow at each plane was calculated using a discretized form of the continuity equation:

$$
\dot{m}=\sum \dot{m}_{i}=\sum V_{i} \cdot A_{i} \cdot \rho
$$

where $V_{i}$ and $A_{i}$ are the individual through-flow velocities and corresponding areas of the plane and

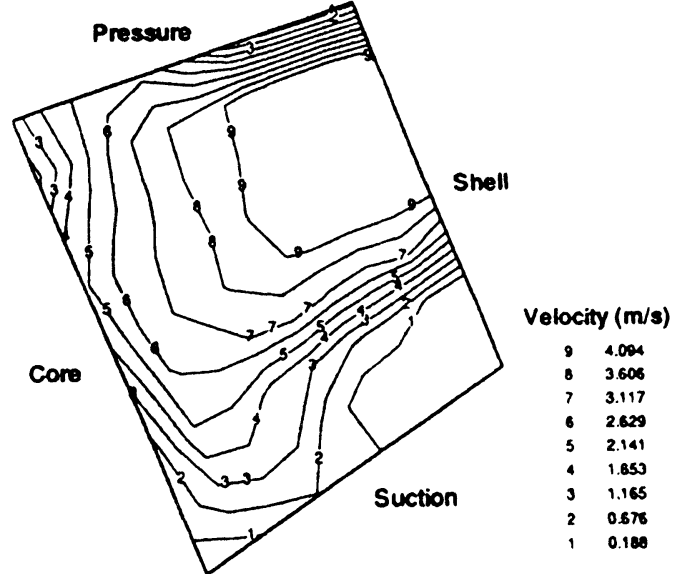

FIGURE 18 Instantaneous through-flow velocity contours at the exit plane for $\mathrm{SR}=0.800$ and pump position 1 .

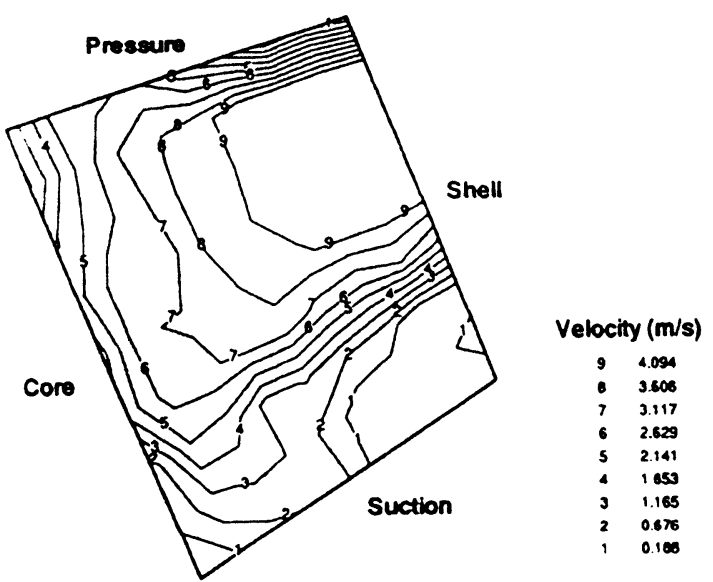

FIGURE 19 Instantaneous through-flow velocity contours at the exit plane for $\mathrm{SR}=0.800$ and pump position 17 .

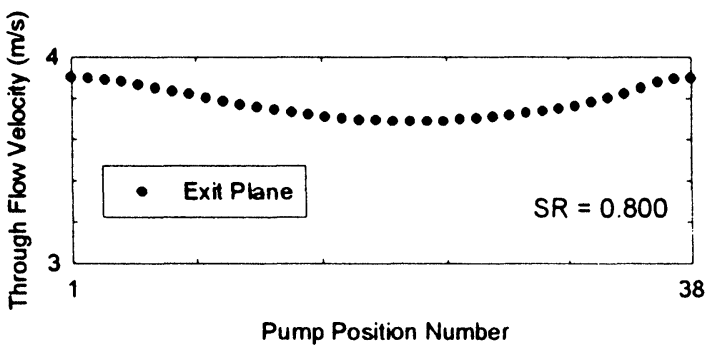

FIGURE 20 Transient through-flow velocity at the passage center as a function of pump position. 


\begin{tabular}{lcc}
\multicolumn{2}{c}{ TABLE IV } & Stator mass flow rates $(\mathrm{kg} / \mathrm{s})$ \\
\hline Plane & \multicolumn{2}{c}{ SR } \\
\cline { 2 - 3 } & 0.065 & 0.800 \\
\hline Inlet & $17.0 \pm 2.6$ & $114 . \pm 1.2$ \\
$1 / 4$ & & $13.0 \pm 1.7$ \\
Mid & $19.6 \pm 3.9$ & $13.4 \pm 2.2$ \\
$3 / 4$ & & $13.2 \pm 2.6$ \\
Exit & $18.1 \pm 3.3$ & $12.4 \pm 3.4$ \\
\hline
\end{tabular}

$\rho$ is the oil density. The mass flow rates and uncertainties are presented in Table IV.

The mass flow rates agree within the given uncertainties from plane to plane for each speed ratio. The mass flow rates also agree with those previously published for the pump (Gruver et al., 1996) and turbine (Brun and Flack, 1997a). Optical difficulties prohibited the acquisition of velocity data along the pressure side and the suction side of the inlet plane blade passage and, therefore, the area measured was less than the actual area of the stator inlet. As a result, the calculated mass flows are lower in the inlet plane than in the other stator measurement planes. The exit plane has the highest mass flow uncertainties of any plane at the 0.800 speed ratio.

\section{CONCLUSIONS}

The flow field in the stator of a Plexiglas model automotive torque converter was studied using laser velocimetery. Five planes in the stator were studied at a speed ratio of 0.800 and three planes were studied at a speed ratio of 0.065 . Stator mass flows and uncertainties were calculated based on the velocity data. Data complements previously available pump and turbine data for the same torque converter and same conditions. Specific conclusions are:

(1) Flow in the stator inlet plane is highly nonuniform due to the complicated flow exiting the turbine.
(2) At the 0.800 speed ratio, separation regions are located in the $1 / 4$ and mid-planes in the corepressure corner region. In the $3 / 4$ and exit planes, separation regions are located in the shell-suction corner.

(3) In the inlet plane a region of high velocities is located along the shell near the pressure side for $\mathrm{SR}=0.800$. The high velocity region has migrated to the shell-suction corner and suction side in the $1 / 4$ and mid-planes.

(4) The overall velocity field for the speed ratio of 0.065 changes significantly from the inlet plane to the mid-plane. The velocity magnitude generally decreases from the suction to the pressure side of the inlet plane and the general direction of the tangential velocity is from pressure-to-suction.

(5) At a speed ratio of 0.065 a strong secondary flow in the inlet from suction surface to pressure surface was seen. However, at $\mathrm{SR}=0.800$ a moderate secondary flow in the inlet from pressure surface to suction surface was observed.

(6) Mass flow rates at the different planes are within the experimental uncertainty and also within the uncertainty of pump and turbine mass flow rates published previously.

(7) At the 0.800 speed ratio, the data in the stator inlet plane are significantly influenced by the turbine relative blade position. The turbine influence on the mid-plane data is significantly less than on the inlet plane data.

(8) At the 0.800 speed ratio, the influence of the pump blade position on the stator exit plane is small compared to the turbine influence on the inlet plane.

\section{Acknowledgments}

This research was sponsored by General Motors Corporation Powertrain Division. The authors wish to express their gratitude to D. Maddock for his technical and hardware support. The research was also supported in part by the Rotating 
Machinery and Controls Laboratory at the University of Virginia.

\section{References}

Ainley, S.B. (1994) Laser velocimetry measurements in the stator and pump of an automotive torque converter M.S. Thesis, University of Virginia.

Ainley, S.B., Flack, R.D., Brun, K. and Rovello, T.J. (1998) Laser velocimeter measurements in the pump of an automotive torque converter, Part I - Effect of speed ratio, accepted for publication in International Journal of Rotating Machinery.

Brun, K. and Flack, R.D. (1994) A method to measure periodic velocity fields in multi-element turbomachines with discrete sampling, Measurement Science and Technology, 5, 418-425.

Brun, K., Flack, R.D. and Gruver, J.K. (1996) Laser velocimeter measurements in the pump of an automotive torque converter, Part II - Unsteady measurements, ASME Transactions, Journal of Turbomachinery, 118, 570-577.

Brun, K. and Flack, R.D. (1997a) Laser velocimeter measurements in the turbine of an automotive torque converter, Part I - Average measurements, ASME Transactions, Journal of Turbomachinery, 119, 646-654.

Brun, K. and Flack, R.D. (1997b) Laser velocimeter measurements in the turbine of an automotive torque converter, Part II - Unsteady measurements, ASME Transactions, Journal of Turbomachinery, 119, 655-662.

By, R.R. (1993) An investigation of three-dimensional flow fields in the automotive torque converter, Doctoral Dissertation, Pennsylvania State University.
By, R.R. and Lakshminarayana, B. (1995) Measurement and analysis of static pressure field in a torque converter pump, ASME Transactions, Journal of Fluids Engineering, 117 109-115.

Dong, Y., Lakshminarayana, B. and Maddock, D.G. (1997) Steady and unsteady flow field at pump and turbine exit of a torque converter, 1997 ASME Fluid Engineering Division Summer Meeting, Vancouver, June 22-26, ASME pape FEDSM97-3351.

Flack, R.D., Ainley, S.B., Brun, K. and Whitehead, L.D. (1998) Laser velocimeter measurements in the pump of an automotive torque converter, Part II - Effect of pump speed and oil viscosity, accepted for publication in International Journal of Rotating Machinery.

Gruver, J.K., Flack, R.D. and Brun, K. (1996) Laser velocimeter measurements in the pump of a torque converter, Part I - Average measurements, ASME Transac tions, Journal of Turbomachinery, 118, 562-569.

Marathe, B.V. and Lakshminarayana, B. (1995) Experimental investigation of steady and unsteady flow field downstream of an automotive torque converter turbine and stator. International Journal of Rotating Machinery, 2 67-84.

Marathe, B.V., Lakshminarayana, B. and Dong, Y. (1996) Experimental and numerical investigation of stator exit flow field of an automotive torque converter, ASME Transactions, Journal of Turbomachinery, 118, 835-843.

von Backström, T.W. and Lakshminarayana, B. (1996) Fluid dynamics and performance of automotive torque converters: an assessment, Journal of Fluids Engineering, 118, 665-676.

Watanabe, H., Kurahashi, T. and Kojima, M. (1997) Flow visualization and measurement of torque converter stator blades using a laser sheet lighting method and a laser velocimeter, SAE Paper No. 970680. 


\section{ait \\ ENERGY MATERIALS}

M A N E Y publishing

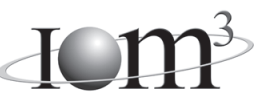

\section{Materials Science \& Engineering for Energy Systems}

Maney Publishing on behalf of the Institute of Materials, Minerals and Mining

The Institute of Materials, Minerals \& Mining

Economic and environmental factors are creating ever greater pressures for the efficient generation, transmission and use of energy. Materials developments are crucial to progress in all these areas: to innovation in design; to extending lifetime and maintenance intervals; and to successful operation in more demanding environments. Drawing together the broad community with interests in these areas, Energy Materials addresses materials needs in future energy generation, transmission, utilisation, conservation and storage. The journal covers thermal generation and gas turbines; renewable power (wind, wave, tidal, hydro, solar and geothermal); fuel cells (low and high temperature); materials issues relevant to biomass and biotechnology; nuclear power generation (fission and fusion); hydrogen generation and storage in the context of the 'hydrogen economy'; and the transmission and storage of the energy produced.

As well as publishing high-quality peer-reviewed research, Energy Materials promotes discussion of issues common to all sectors, through commissioned reviews and commentaries. The journal includes coverage of energy economics and policy, and broader social issues, since the political and legislative context influence research and investment decisions.

\section{CALL FOR PAPERS}

Contributions to the journal should be submitted online at http://ema.edmgr.com

To view the Notes for Contributors please visit: www.maney.co.uk/journals/notes/ema

Upon publication in 2006, this journal will be available via the Ingenta Connect journals service. To view free sample content online visit: www.ingentaconnect.com/content/maney

For further information please contact:

Maney Publishing UK

Tel: +44 (0)113 2497481 Fax: +44 (0)1132486983 Email: subscriptions@maney.co.uk

or

Maney Publishing North America

Tel (toll free): 8662975154 Fax: 6173546875 Email: maney@maneyusa.com

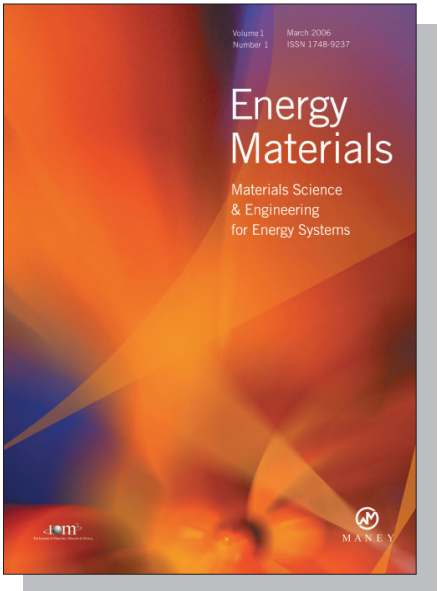

EDITORS

Dr Fujio Abe

NIMS, Japan

Dr John Hald, IPL-MPT, Technical University of Denmark, Denmark

Dr R Viswanathan, EPRI, USA

\section{SUBSCRIPTION INFORMATION}

Volume 1 (2006), 4 issues per year

Print ISSN: 1748-9237 Online ISSN: 1748-9245

Individual rate: $£ 76.00 / U S \$ 141.00$

Institutional rate: $£ 235.00 /$ US $\$ 435.00$

Online-only institutional rate: $£ 199.00 / U S \$ 367.00$

For special $\mathrm{IOM}^{3}$ member rates please email

subscriptions@maney.co.uk

\section{For further information or to subscribe online please visit www.maney.co.uk}



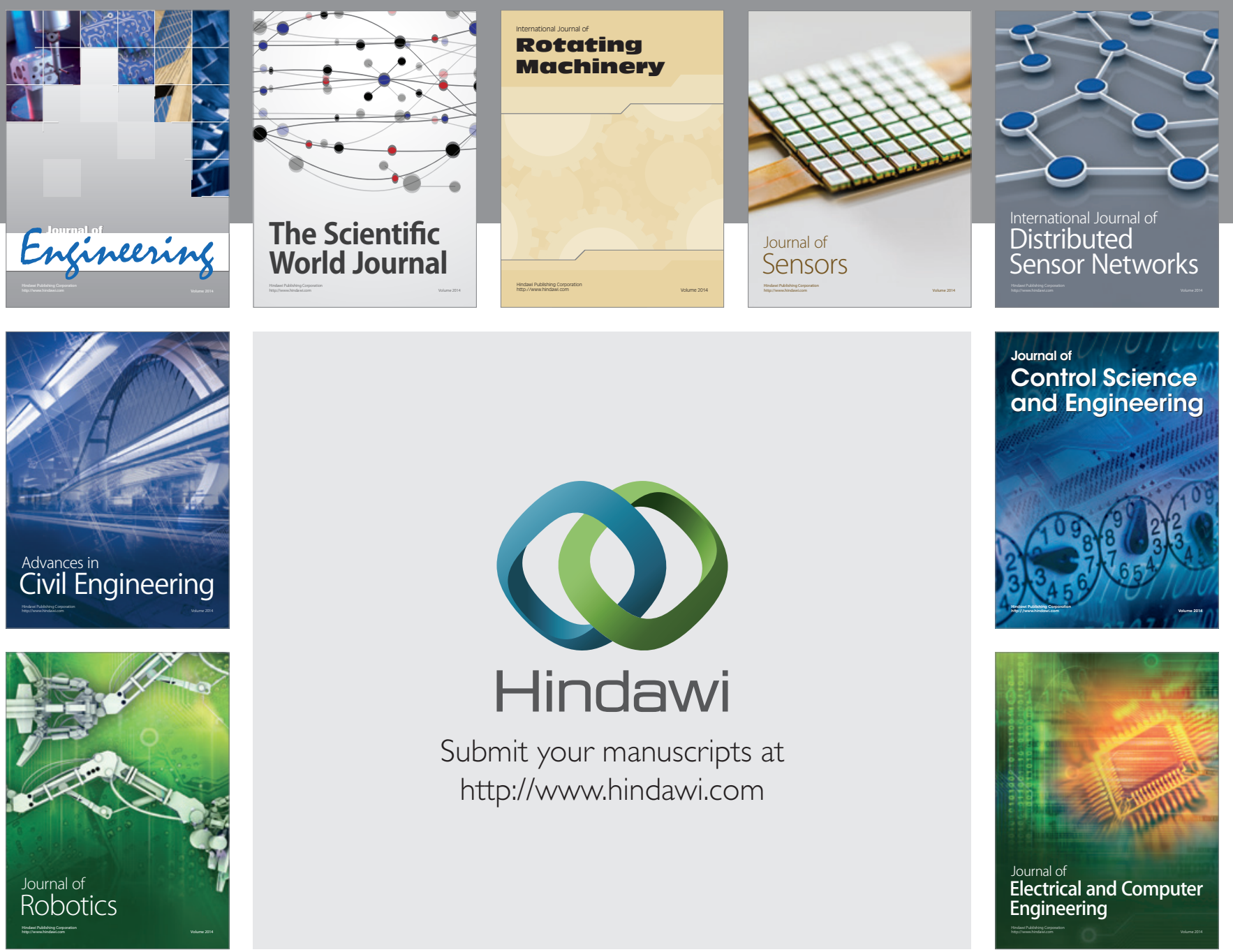

Submit your manuscripts at

http://www.hindawi.com
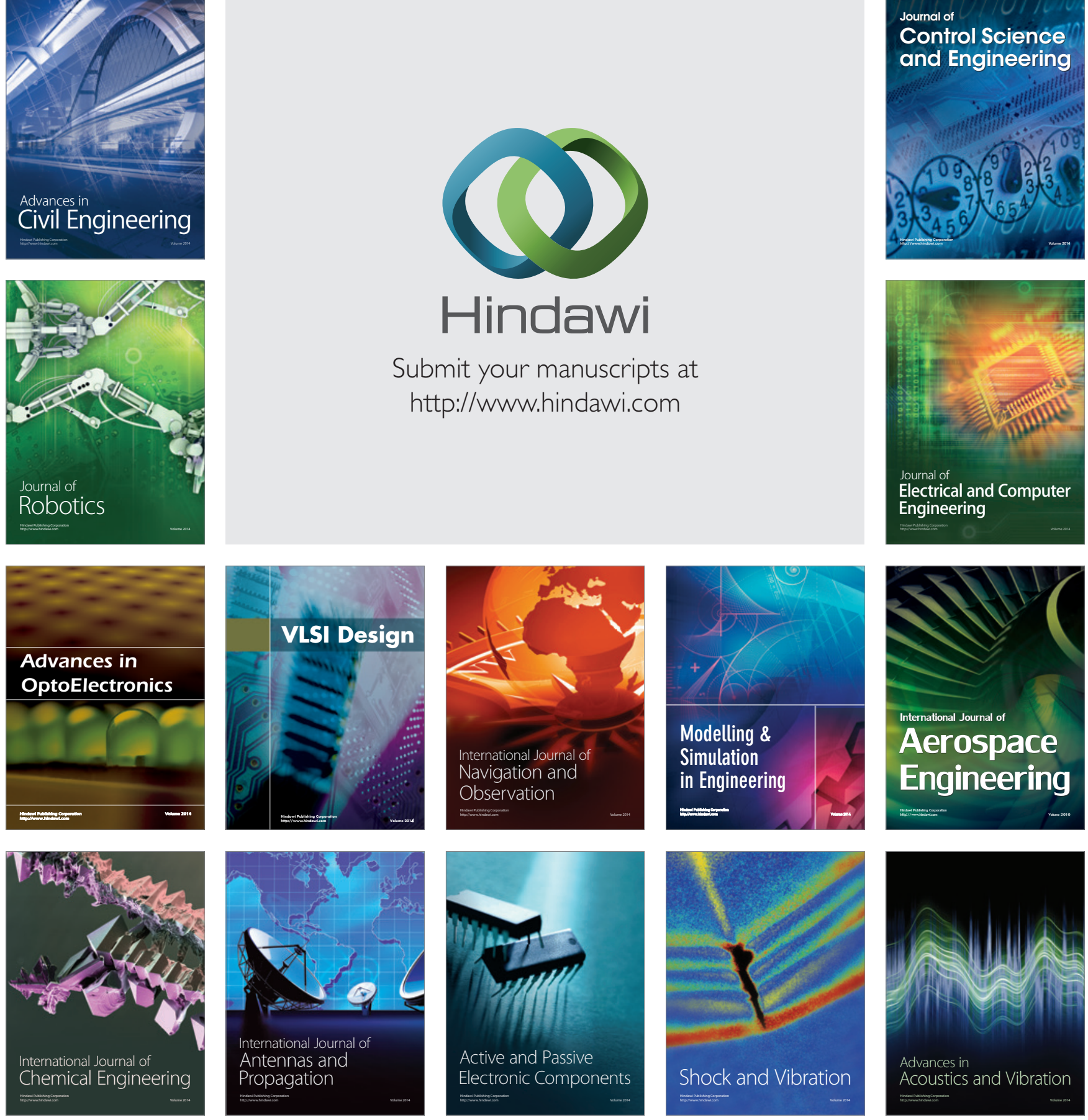